\title{
FORMAÇÃO CONTINUADA DE PROFESSORES NA PERSPECTIVA DA EDUCAÇÃO NO CAMPO
}

\author{
Vanessa Cristina Pimentel ${ }^{1}$ \\ Diógenes José Gusmão Coutinho²
}

RESUMO: O presente artigo, tem como objetivo, apresentar o processo formativo dos educadores, a importância que esse apoio tem para os professores. $O$ texto em um formato introdutório e reflexivo, foi elaborado através de levantamento bibliográfico voltado à temática trabalhada e traz bases dos documentos oficiais. Com um olhar sobre a prática desse processo no trabalho pedagógico do professor da escola do campo. Compreendendo-se que, a escola do campo tem suas particularidades de existência relacionadas a educação, se faz necessário, educadores que entendam e atendam a essa especificada modalidade do campo. Partindo dessa compreensão sobre as peculiaridades da educação do campo, é que se compreende sobre a importância de ofertar ao educador, formação continuada na busca de uma educação de qualidade e voltada para realidade do aluno onde o professor possa aprender sobre esse espaço chamado- comunidade do campo. Com tudo, foi mostrado o papel da formação continuada, principalmente para os professores do campo, pois é nesse processo que os profissionais da educação têm uma vasta visão e reflexão sobre suas técnicas pedagógicas.

Palavras-Chave: Formação de professores. Educação do campo. Especificidades. Professores do campo.

\section{CONTINUING TRAINING OF TEACHERS IN RESEARCH EDUCATION RESEARCH}

ABSTRACT: This article aims to present the educators' training process, the importance that this support has for teachers. The text, in an introductory and reflective format, was prepared through a bibliographic survey focused on the theme worked on and brings the bases of the official documents. With a look at the practice of this process in the pedagogical work of the rural schoolteacher. Understanding that, the rural school has its particularities of existence related to education, it is necessary educators who understand and attend to this specific field modality. Based on this understanding of the peculiarities of rural education,

\footnotetext{
${ }^{1}$ Graduada em Pedagogia pela UNOPAR. Especialização em Psicopedagogia Institucional, Clínica e Hospitalar pela FAVAPI Aluna de Especialização em Pesquisa Avançada pela Faculdade Alpha, Mestrado Internacional EAD pela Atenas College University. E-mail: vam_pe@hotmail.com.

2 Graduado em Biologia pela UFRPE. Doutor em Biologia pela UFPE. E-mail: alphadiogenes@gmail.com.
} 


\section{Universidade do Extremo Sul Catarinense \\ Revista Ibero-Americana de Humanidades, Ciências e \\ Educação \\ Unesc Produção e democratização do conhecimento na llbero-América}

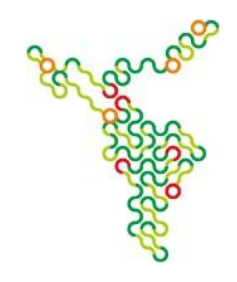

it is possible to understand the importance of offering the educator continuing education in the search for quality education and focused on the student's reality where the teacher can learn about this space called the rural community. However, the role of continuing education was shown, especially for teachers in the field, as it is in this process that education professionals have a wide view and reflection on their pedagogical techniques.

Keywords: Teacher training. Rural education. Specificities. Field teachers.

\section{INTRODUÇÃO}

É visível as mudanças que estão acontecendo a todo tempo e toda hora com a educação escolar. Considerando essa observação, pode-se dizer que o conhecimento, que é o que rege a vida do ser humano, está passando também por uma transformação e adequação a esses novos tempos. Nesse contexto, visando a escola como um lugar de sabres e o educador como uma ponte para o conhecimento, se faz necessário que os mesmos também se adéquem a essas novas mudanças. A escola precisa se adaptar para receber os alunos dessa nova geração globalizada e tecnológica. Contrapartida, os profissionais da educação precisam estarem atualizados para que possam atender melhor essa nova geração que são ansiosas por respostas rápidas a tudo, que estão envolvidos nas questões culturais, sociais, econômicas e políticas do seu meio de vivência.

De acordo com as pesquisas de Monteiro e Nunes (2010, p.269) "A formação inicial e continuada dos docentes necessita atender as essas responsabilidades de ajudar a construir e reconstruir outras identidades, pessoal/social e outras profissionalidades individual/coletiva com base em formações reflexivas e crítica".

Para tal contexto, se faz necessário ofertar o processo formativo para professores, com a finalidade de atualizar as ações pedagógicas desses profissionais. Fazer com que o profissional reveja suas práticas educacionais, buscando sempre a melhor forma de repasse dos saberes aos educandos. E, se tratando da educação do campo, esse processo de formação continuada tem que ser específico, diferencia e direcionado a comunidade escolar do campo. Incluindo sim, todos os avanços educacionais e tecnológicos dos tempos atuais, mas também, respeitando o modo de vida em comunidade, sua cultura, enfim, a 


\section{Universidade do Extremo Sul Catarinense \\ Revista Ibero-Americana de Humanidades, Ciências e \\ Educação \\ Unesc Produção e democratização do conhecimento na lbero-América}

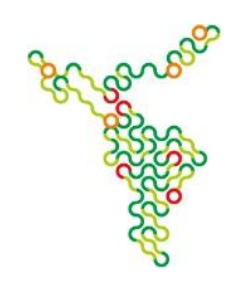

identidade do povo do campo. De acordo com Monteiro e Nunes (2010, p. 274)

Tomar como referência o ambiente cultural implica respeitar e considerar a história e a cultura desse povo. Por esses motivos, acolher as identidades do campo ajuda os professores a melhor preparar os alunos, e ir além das primeiras impressões ao aprender a enfrentar muitas circunstâncias dilemáticas em sua trajetória de vida pessoal e profissional, para mudar a si próprio, o outro e o contexto.

A atuação do professor e suas práticas pedagógicas têm que estarem interligadas a realidade da escola do campo, da educação do campo, para que assim, o processo de troca de saberes aconteça na íntegra. Por isso, que se faz tão importante a formação continuada para professores do campo, e assim, haja um olhar mais especificado a essa educação.

E assim, é com esse intuído de mostrar o qual importante é a formação continuada para professores, em um todo, mas em especial, para os professores atuantes nas escolas do campo, onde que, para se fazer um trabalho educacional de verdade, o educador tem que ser para o campo e do campo.

\section{METODOLOGIA}

O presente trabalho foi elabora com o objetivo de mostrar o qual importante se faz necessário a oferta da formação continuada de professores, em um todo, como também com especificidades dessa formação para os professores da educação do campo.

Trata-se, portanto, de uma pesquisa feita através de um levantamento bibliográfico, ao qual, foi buscado nos documentos oficiais e legais voltadas à educação e, ao tema abordado, para assim, dar o embasamento teórico necessário e veracidade ao texto proposto. Para um melhor aprofundamento no assunto, foram utilizados livros, artigos relacionados o tema da pesquisa e sites na internet.

Desse modo, foi possível fazer uma análise reflexiva acerca do processo formativo para professores e sobretudo, causar um novo olhar através de novas e futuras discussões sobre o tema.

\section{FORMAÇÃO CONTINUADA PARA PROFESSORES - DESCREVENDO SUA IMPORTÂNCIA}




\section{Universidade do Extremo Sul Catarinense \\ Revista Ibero-Americana de Humanidades, Ciências e \\ Educação \\ UnesC Produção e democratização do conhecimento na lbero-América}

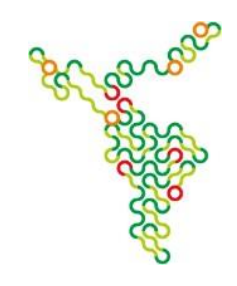

Não se pode negar que, um bom método pedagógico no trabalho educacional contribui muito para a aprendizagem dos alunos. Para tanto, o professor deve buscar as várias formas para alcançar essa aprendizagem total do estudante sobre determinados conteúdos e, a consciência do professor de que precisa fazer uso de vários métodos para chegar ao aluno, é de extrema importância. Ao qual, sabe-se que, o papel do professor e da escola é de promover aos alunos uma formação, não só de saberes educacionais, mas também na construção do sujeito como parte integrante da sociedade.

"É nesse sentido que ensinar não é transferir conhecimento, conteúdos nem forrar é ação pela qual um sujeito criador dá forma, estilo e alma a um corpo indeciso e acomodado" (FREIRE, 1996, p. 33).

Para tanto, o professor precisa estar munido de conhecimento para poder, assim, repassar os saberes. É o que salienta as Diretrizes Curriculares Nacionais Gerais para a Educação Básica, (BRASIL. 2010, p. 58)

[...] O professor precisa, particularmente, saber orientar, avaliar e elaborar propostas, isto é, interpretar e reconstruir o conhecimento. Deve transpor os saberes específicos de suas áreas de conhecimento e das relações entre as áreas, na perspectiva da complexidade; conhecer e compreender as etapas de desenvolvimento dos estudantes com os quais está lidando.

Além da consciência do professor de saber que estará sempre em busca de novas fórmulas para repasse dos saberes aos educandos, existe um instrumento fundamental de ajuda ao professor que lhe proporciona um novo olhar para novas ideias voltadas a aprendizagem dos alunos, a formação continuada para professores, que como já foi exposto, contribui muito para que o professor tenha sempre uma nova visão do seu trabalho educacional.

Pode-se dizer que, é através da formação continuada para professores que, os mesmos, vão se inovando e buscando cada dia mais o seu espaço no âmbito escolar como formador de saberes. Se pondo como ser reflexivo no conhecimento para assim chegar a ação, pois, é na situação da prática onde o professor se constrói.

Os Parâmetros para a Educação Básica do Estado de PE, traz uma breve 


\title{
Universidade do Extremo Sul Catarinense \\ Revista lbero-Americana de Humanidades, Ciências e \\ Educação \\ Unesc Produção e democratização do conhecimento na lbero-América
}

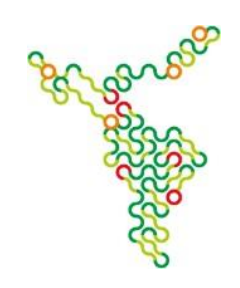

explicação sobre o desenvolvimento inicial desse processo de formação continuada para professores, Pernambuco (2014, p. 33) afirma que:

\begin{abstract}
A formação continuada dos docentes tem apresentado, ao longo de sua trajetória, concepções distintas. Em determinados momentos, o processo de formação continuada foi identificado como capacitação ou treinamento, com o objetivo de suprir as carências da formação inicial dos professores. Com essa perspectiva, eram organizados cursos variados, de acordo com as necessidades dos gestores das redes de ensino e/ou pelos próprios professores.
\end{abstract}

Mostra-se então, nessa explicação muito pertinente, como a formação continuada para professores era vista e ofertada, no pretérito. Uma visão da formação continuada mais voltada à resolução de problemas individuais e imediatos sem um objetivo geral a ser alcançado. Os mesmo Parâmetros, mostra uma visão diferenciada da inicial que foi sendo construída com o passar dos tempos.

Segundo Pernambuco (2014, p. 03) "A formação é compreendida como o espaço de reflexão sobre a prática pedagógica". Essa colocação se faz mais atual para o real sentido e objetivo da formação continuada para professores.

A formação continuada para professores não é só, simplesmente, um encontro para expor experiências nas salas de aula, é sim um compromisso de melhoria do profissional da educação, uma formação de melhoria enquanto pessoa, uma melhoria como formadores de opinião. As Diretrizes Curriculares Nacionais Gerais para a Educação Básica, acrescenta que:

A formação inicial e continuada do professore tem que ser assumida como compromisso integrante do projeto social, político e ético, local e nacional, que contribua para a consolidação de uma nação soberana, democrática, justa, inclusiva e capaz de promover a emancipação dos indivíduos e grupos sociais" (BRASIL, 2010, p.58)

Com tudo, com foi bem explicado, trata-se de um apoio a mais para que consiga alcançar os objetivos na visão educacional na totalidade, e que, esse apoio tem que ser ofertado como um compromisso pelos órgãos competentes para tal questão. Sendo assim, pode-se dizer que, a formação continuada para professores é a estrutura base dos profissionais da educação, ao qual, todos têm que ter acesso a essa base para aprimorar-se e se reconstruir a cada etapa, a 


\section{Universidade do Extremo Sul Catarinense \\ Revista Ibero-Americana de Humanidades, Ciências e \\ Educação}

Unesc Produção e democratização do conhecimento na lbero-América

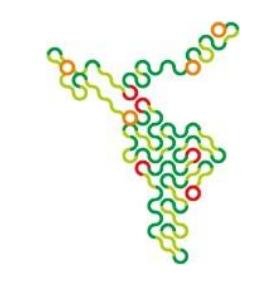

cada ano, a cada turma.

Para tanto, "é preciso, indispensável mesmo, que o professor se ache repousado no saber que a pedra fundamental é a curiosidade do ser humano. É ela que faz perguntar, conhecer, atuar, mais perguntar, reconhecer" (FREIRE, 1996, p.33).

A formação continuada para professores está assegurada como previsto na LDBEN - Lei de Diretrizes e Bases da Educação Nacional 9.394/96 onde mostra que, as Secretarias Municipais de Educação têm essa função, com ou sem apoio dos Estados e da União, de realizar esse trabalho de apoio aos professores das instituições educacionais. Buscando assim, uma melhoria na educação, uma educação de qualidade para os alunos da rede pública, independentemente da modalidade de ensino.

Com tudo, sabemos que isso ainda não é o que ocorre, talvez pela falta de conhecimento sobre a importância desse apoio aos educadores, que não é, para alguns líderes políticos, dinheiro jogado fora ou perda de tempo, e sim, dinheiro investido para uma melhoria que, começa com o profissional da educação e transpassa para os alunos que por fim, reflete no seu espaço de vivência, família, comunidade. Por isso, Freire (2010, p. 33) salienta que, "[...] embora diferentes entre si, quem forma se forma e reforma ao formar e quem é formado forma-se e forma ao ser formado".

Muito propicio e oportuno o que explana o autor, pois, essa é a exata forma da contribuição da formação continuada para professores, um repasse de saberes com qualidade que não fica só com o educador e sim, vai se transpassando.

É importante mostra também que, para mudar o ciclo, pode-se dizer que círculo vicioso ao qual alguns educadores têm, o famoso caderninho amarelado de vários anos com as atividades já prontas, se faz de extrema necessidade e importância, a formação continuada para professores de modo que, esse evento não venha a acontecer no âmbito educacional. Estamos em tempos de tecnologias avançadas, novos tempos de evolução na educação, mesmo assim, ainda existem profissionais da educação que, por comodismo ou até mesmo a falta de apoio pedagógico, entre outros fatores, que optam por esse modelo de 


\section{Universidade do Extremo Sul Catarinense \\ Revista Ibero-Americana de Humanidades, Ciências e \\ Educação \\ UneSC Produção e democratização do conhecimento na lbero-América}

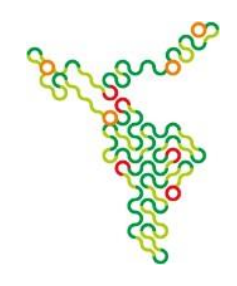

professor, "didática de todos os anos." E esse modelo de profissional/educador que não se encaixa no contexto de formador de conhecimentos, ponte de saberes.

No entanto, não se pode afirmar que, a formação continuada seria o pontochave para mudar a educação, mas pode-se dizer sim que, esse projeto é um apoio muito importante para que o professor se permita enxergar novas possibilidades, se refazer enquanto profissional e se atualizar para compartilhar os saberes com a clientela atendida nas escolas que, estão sempre em constante mudança. Sendo também uma forma de valorização do profissional da educação. É o que diz as diretrizes Curriculares Nacionais Gerais da Educação Básica em seu Art.57:

$\S 1^{\circ}$ A valorização do profissional da educação escolar vincula-se a obrigatoriedade da garantia de qualidade e ambas se associam à exigência de programas de formação inicial e continuada de docentes e não docentes, no contexto do conjunto de múltiplas atribuições definidas para os sistemas educativos, em que se inscrevem as funções do professor. (BRASIL, 2010, p 78).

Com tudo, mostra-se que, muitos são os benefícios na/para educação se tratando da formação continuada para professores, como já foi exposto anteriormente nesse texto. Não se trata apenas de um único beneficiado e sim todos envolvidos na/com educação, professor - aluno - escola - sociedade sistema educacional. Todos ganham com uma educação de qualidade.

\section{FORMAÇÃO CONTINUADA DE PROFESSORES - PROFESSORES DO/PARA O CAMPO}

Inserida no sistema educacional como uma modalidade de ensino, que é o que nos mostra as Diretrizes Curriculares Nacionais Gerais para a Educação Básica na Resolução CNE/CEB n.. 04, de 13 de julho de 2010, a educação do campo vem sempre buscando seu espaço no âmbito educacional. E, a busca por esse espaço foi sempre movida por muita luta pelos povos residentes nos espaços rurais. Educação por direito e de qualidade nos seus lugares de moradia. Como, também, uma educação voltada a realidade dos povos inseridos no campo. Nesse sentido, as Diretrizes Curriculares Nacionais Gerais para a Educação Básica, acrescenta que: 


\section{Universidade do Extremo Sul Catarinense \\ Revista lbero-Americana de Humanidades, Ciências e \\ Educação \\ UnesC Produção e democratização do conhecimento na lbero-América}

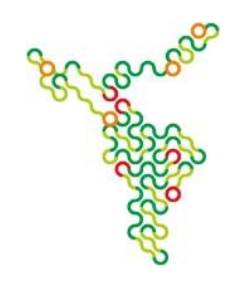

Art. 36. A identidade da escola do campo, é definida pela vinculação com as questões inerentes à sua realidade, com propostas pedagógicas que contemplam sua diversidade em todos os aspectos, tais como sociais, culturais, políticos, econômicos, de gênero, geração e etnia." (BRASIL,2010, p.73).

Pode-se dizer que, a educação do campo tem suas peculiaridades para se fazer existir. Não se trata de uma educação especial, mas sim com suportes específicos para atender as necessidades das comunidades do campo. Para essas necessidades serem percebidas, precisa-se vir a ter um olhar para o todo, um olhar para além do território do campo e sim, também para a cultura, o modo de vida... como se faz muito explicito no exposto pelo artigo 36 citado anteriormente.

Mas, o sentido de trabalhar com a realidade existente no campo, não quer dizer que o trabalho educativo será feito para que a comunidade atendida se acomode à ideia de fixação no campo, sem perspectivas de crescimento ou desenvolvimento, mas sim que, com o conhecimento educacional busquem novas reflexões sobre sua comunidade, seus ideais de vida. Assim, salienta as Diretrizes Curriculares Nacionais da Educação Básica, em Consultas referentes às orientações para o atendimento da Educação do Campo.

\footnotetext{
Não se trata, é claro, da ideia errônea de pretender fixar o homem rural no campo, uma vez que o processo educativo deve criar oportunidades de desenvolvimento e realização pessoais e sociais; trata-se, entretanto, de trabalhar sobre as demandas e necessidades de melhorias[...]" (BRASIL, 2010, p. 288).
}

Com os marcos normativos legais, voltado para Educação do Campo, através do PRONERA - Programa Nacional de Educação na Reforma Agrária, em seu Decreto $n .-7.352$, de 4 de novembro de 2010, mostra a seguridade da formação de profissionais para atuar nas escolas do campo:

Art. 2o , inciso II - Desenvolvimento de políticas de formação de profissionais da educação para 0 atendimento da especificidade das escolas do campo, considerando-se as condições concretas da produção e reprodução social da vida no campo (BRASIL, 2010, p. 82)

Esse é um dos princípios para que o trabalho na educação do campo seja voltado para a realidade e a identidade dessas comunidades rurais. Com tudo, esse olhar que se faz necessário ao atendimento da educação do campo, os 


\section{Universidade do Extremo Sul Catarinense \\ Revista Ibero-Americana de Humanidades, Ciências e \\ Educação \\ UnesC Produção e democratização do conhecimento na lbero-América}

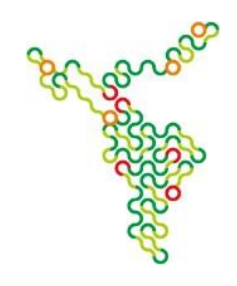

profissionais da educação que trabalham nesse espaço rural, também terão que ter algumas especificidades para realizar um trabalho educacional voltado para 0 campo.

Mostra-se claramente, através dos documentos legais direcionados à educação no campo, as necessidades específicas que a educação do campo precisa. Onde se inclui os docentes atuantes nessas áreas. Para atender as necessidades das escolas do campo, se faz necessário ser um profissional que entenda todas essas peculiaridades existentes no campo. É aí que entra a tão importante questão da formação continuada para professores.

Se faz necessário mostrar a realidade ao qual vai se trabalhar, explicar sobre as questões ali existentes, formar 0 professor para 0 atendimento à educação do campo. É o que ainda salienta o PRONERA no mesmo decreto Art. $4^{\circ}$, inciso $\mathrm{VI}$ - Formação inicial e continuada específica de profissionais que atendam às necessidades de funcionamento do campo (BRASIL, 2010, p.84).

A Resolução n.. 2, de 28 de abril de 2008, também assegura a importância dos profissionais atuantes na educação do campo de terem formação inicial e/ou continuada apropriada para tal comunidade. E ainda mostra que, não se trata só dos educadores, e sim, de todos que atuem nas escolas das áreas rurais.

Art.,7.. parágrafo $\S 2 . .^{\circ}$ A admissão e a formação inicial e continuada dos professores e do pessoal de magistério de apoio ao trabalho docente deverão considerar sempre a formação pedagógica apropriada à Educação do Campo e às oportunidades de atualização e aperfeiçoamento com os profissionais comprometidos com suas especificidades (BRASIL,2010, p.296).

De acordo com Arroyo (2012, p. 363):

As necessidades ao qual tanto se declara, é simplesmente que o educador seja do campo, que entenda o território rural e suas necessidades, que trabalhe junto com a comunidade, respeitando seu modo de vida, sua identidade. para o campo, que faça o seu papel enquanto multiplicador de saberes, que traga as novidades que envolvem o contexto educacional e que essas novidades venham a somar com/para a realidade do campo. Que haja, com tudo, uma troca de saberes e experiências. [...] reconhecer os saberes do trabalho, da terra, das experiências e das ações coletivas sociais [...]

Com tudo, esse processo formativo, chamada formação continuada para 


\section{Universidade do Extremo Sul Catarinense \\ Revista Ibero-Americana de Humanidades, Ciências e \\ Educação \\ UnesC Produção e democratização do conhecimento na lbero-América}

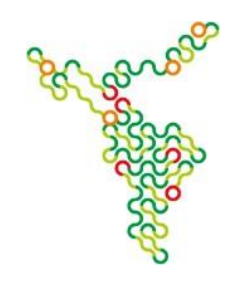

professores, em especial os educadores do campo, só vem a favorecer o desenvolvimento pessoal/profissional dos professores atuantes nas escolas do campo e assim ir se construindo uma educação de respeito e de qualidade.

\section{RESULTADOS E DISCUSSÃO}

A educação voltada ao campo está sempre em alta nas discussões que envolvem o sistema educacional na totalidade. E, para tanto, trata-se de uma modalidade de ensino que traz uma história regada de lutas por um olhar de valorização e direitos de se fazer existir.

Dentro desse contexto de escola do campo, estão os professores que, para atender a essa modalidade tão peculiar, se faz necessário que entendam a identidade dessa comunidade. $\mathrm{E}$, o mecanismo que faz com que os professores compreendam o seu lugar de trabalho enquanto território e comunidade está na oferta do processo formativo para esses professores.

Para tal pesquisa, foram definidos alguns objetivos principais: ressaltar o direito dos professores à oferta da formação continuada; apresentar a importância dessa formação como uma forma de reciclagem das práticas pedagógicas; o desenvolver desse processo formativo com o reflexo na melhoria da qualidade da aprendizagem dos alunos.

E, com esses mesmos objetivos citados acima, incluem-se as escolas do campo. Ao inseri-la, através também da formação continuada para professores, vem junto algumas reflexões como, o que trabalhar e como trabalhar com a educação do campo, pelo simples fato desses lugares terem muitas especificidades em todo seu contexto.

Assim, a pesquisa aponta, pode-se dizer como resultado, mediante todos os objetivos ressaltados anteriormente, que o processo formativo tem uma grande valorização na construção e reconstrução das práticas pedagógicas dos professores do campo. Pois, mostrou-se que, é através desses momentos formativos onde o professor tem o real conhecimento da realidade existente na educação no campo e, com isso, podem nortear-se às novas possibilidades de reinventar sua prática no pessoal/profissional. 


\section{Universidade do Extremo Sul Catarinense \\ Revista Ibero-Americana de Humanidades, Ciências e \\ Educação \\ UnesC Produção e democratização do conhecimento na lbero-América}

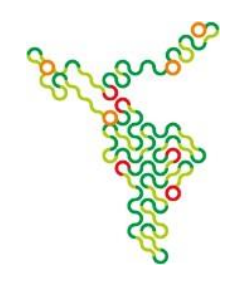

Partindo de uma visão informativa e reflexiva dos autores, essa pesquisa abre novos relevantes debates a cerca dessa modalidade de educação do campo onde sempre estará em foco no sistema educacional nacional.

\section{CONSIDERAÇÕES FINAIS}

Pode-se dizer que, a escola é um ambiente onde deve-se aprenderensinar, onde há troca de conhecimentos, experiências e saberes tanto do educador para com o aluno e/ou vice-versa. Independentemente de onde esteja localizada essa escola, na cidade ou no campo, esse deve ser o contexto principal desse espaço.

O presente artigo, explanou a importância do processo formativo, em um olhar geral, para os profissionais da educação. A importância de fazer com que o professor busque novas metodologias para com o trabalho pedagógico. Salientou que, se faz necessário ofertar essa formação continuada para professores. É necessário, que se atenda esse direito. Direito esse, ao qual, essa pesquisa mostrou os documentos oficiais que asseguram esse direito aos professores.

O texto, tendo também seu contexto principal o foco na formação continuada para professores do campo, mostrou a importância dessa formação continuada, que também, no que lhe concerne, se faz assegurara pelos documentos legais voltados à educação no campo. Para entender e fazer um bom trabalho educacional voltado para as comunidades rurais, se faz necessário, profissionais que atendam as peculiaridades das escolas do campo.

Onde, a formação continuada especifica para esse tipo de modalidade, só traz benefícios para o todo, e nesse todo, se inclui primeiramente, o próprio educador que fará novas descobertas para realização do seu trabalho; depois vem os alunos, que terão um ensino aprendizagem de mais qualidade e, junto desses alunos vem a escola e a comunidade que acabam se moldando a novas descobertas, conhecimentos e experiências.

Com tudo, diante de toda essa explanação benéfica sobre a formação continuada para os professores e/do campo pode-se dizer que, esse processo formativo é de extrema importância para que os educadores se busquem, se 


\section{Universidade do Extremo Sul Catarinense \\ Revista lbero-Americana de Humanidades, Ciências e \\ Educação \\ UneSC Produção e democratização do conhecimento na lbero-América}

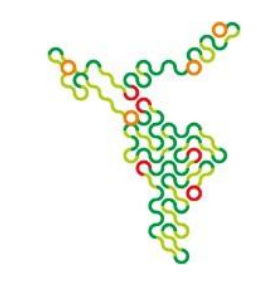

refaçam, se reformem em suas práticas buscando melhorias no pessoal/profissional e assim, ofertem uma educação de qualidade, trabalhando com as realidades e especificidades que compõem o ambiente escolar nesse espaço chamado campo.

\section{REFERÊNCIAS}

ARROYO, Miguel Gonzalez. Formação de Educadores do Campo. Rio de Janeiro. P. 361-367. 2012.

BRASIL. Diretrizes Curriculares Nacionais da Educação Básica. Brasília, 2010, p. 58.

BRASIL. Diretrizes Curriculares Nacionais da Educação Básica. Consulta referente às orientações para o atendimento da Educação do Campo. Brasília,2010. p. 288.

BRASIL. Lei de Diretrizes e Bases da Educação. Lei o 9394/96, de 20 de dezembro de 1996. Diário Oficial da União, Brasília, DF.

BRASIL. Ministério da Educação. Decreto n7 352, de 04 de novembro de 2010. Dispõe sobre a política de educação do campo e o Programa Nacional de Educação na Reforma Agrária - PRONERA. Brasília, 2012 a. p. 82.

CNE/CEB Resolução no4, de 13 de julho de 2010, seção IV. Brasília, 2010. p.73.

CNE/CEB. Resolução no4, de 13 de julho de 2010Capitulo IV. Brasília, 2010. p. 78.

Consulta referente às orientações para o atendimento da Educação do Campo. Brasília, 2010. p. 296.

Decreto n־7 352, de 04 de novembro de 2010. Dispõe sobre a política de educação do campo e o Programa Nacional de Educação na Reforma Agrária PRONERA. Brasília, 2012 b. p. 84. 


\section{Universidade do Extremo Sul Catarinense}

Revista Ibero-Americana de Humanidades, Ciências e

Educação

Unesc Produção e democratização do conhecimento na lbero-América

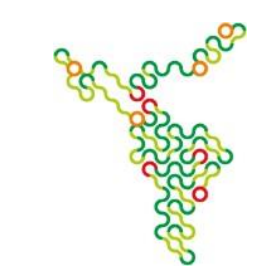

FREIRE, Paulo. Pedagogia da Autonomia. Saberes necessários à prática educativa. São Paulo, Brasil: paz e Terra, 1997. p. 33. (Coleção Leitura).

MONTEIRO, Albene Lins; NUNES, Celi de Socorro Costa. Formação continuada de professores de classes multisseriadas do campo: perspectivas, contradições, recuos e continuidade. Escola de direito: reinventando a escola multisseriada. Belo Horizonte: Autêntica, 2010. p.263-282.

PERNAMBUCO. Parâmetros para a Educação Básica do Estado de Pernambuco.

Parâmetros de Formação Docente Ciências da Natureza e Matemática. Pernambuco, 2014. 